\title{
Effects of Biochar on Soluble Sugar Content in Peach Seedlings
}

\author{
Jing Sun ${ }^{1}$, Zhiyu $\mathrm{Li}^{2}$, Jinpeng Zhu², Yuxi Wang ${ }^{2}$, Tonghao Cui ${ }^{2}$ and Lijin $\operatorname{Lin}^{1 *}$ \\ ${ }^{1}$ Institute of Pomology and Olericulture, Sichuan Agricultural University, Chengdu, Sichuan, 611130, China \\ ${ }^{2}$ College of Horticulture, Sichuan Agricultural University, Chengdu, Sichuan, 611130, China
}

\begin{abstract}
A pot experiment was conducted to study the effects of different biochar types [addition of rape straw biochar (RB), addition of paddy straw biochar (PB), addition of wheat straw biochar (WB) and addition of corn straw biochar (MB)] on the soluble sugar content and plant height of peach seedlings. The result showed that the soluble sugar content in roots and leaves of peach seedlings treated with biochar was lower than the control. However, the soluble sugar content in stems was higher than control compared with the control. In the soluble sugar content in the aboveground part, there was no significant difference between the treatment of adding biochar and the control except for the treatment of PB. All the treatment of adding biochar increased the plant height of peach seedlings except the treatment of MB than the control and the treatment of RB and PB were at a higher level. Compared to control, all biochar addition treatments increased stem diameter of peach seedlings and the treatment of RB and PB were at a higher level. Therefore, the treatment of RB and PB was beneficial to the growth of peach seedlings.
\end{abstract}

\section{Introduction}

Biochar is a carbon-rich product produced by incomplete combustion of biomass under anoxic conditions, based on the widely existing biomass resources in nature and using specific carbonization technology [1]. When biomass carbonization is returned to the field, it can change the physical properties and structure of the soil, thus improving soil fertility, indirectly improving crop nutrient use efficiency, promoting crop growth and increasing crop yield [2-6]. In the study, black carbon could promote maize seedling growth, and its plant height and stem diameter increased by $4.31-13.13 \mathrm{~cm}$ and $0.04-0.18 \mathrm{~cm}$, respectively, compared with the control [7]. The study shows that the activities of sucrase, polyphenol oxidase and cellulase in rhizosphere soil of Chinese cabbage increase significantly with the increase of biochar application, which promotes the growth of Chinese cabbage and increases the content in soluble sugar in leaves [8]. Different straw biochar has different effects on soybean growth, rhizosphere soil organic carbon and microbial community functional diversity [9]. In this experiment, peach seedlings was used as the research object to study the growth status of peach seedlings after applying four different straw biochar, so as to select the most suitable biochar for peach seedling growth.

\section{Materials and methods}

\subsection{Materials}

\footnotetext{
*Corresponding author's e-mail: 1lj800924@qq.com
}

Peach seeds were purchased from a market in Chengdu, Sichuan, China. Non-polluted soil was collected from the Chengdu campus of Sichuan Agricultural University $\left(30^{\circ} 42^{\prime} \mathrm{N}, 103^{\circ} 51^{\prime} \mathrm{E}\right)$ in Chengdu, Sichuan, China. The basic soil properties were as follows: $\mathrm{pH}, 7.71$; organic matter content, $15.29 \mathrm{~g} / \mathrm{kg}$; alkaline nitrogen content, $87.99 \mathrm{mg} / \mathrm{kg}$; available phosphorus content, $55.77 \mathrm{mg} / \mathrm{kg}$; and available potassium content, $41.96 \mathrm{mg} / \mathrm{kg}$. The basic physical and chemical properties of the soil were based on references [10]. The rape straw, paddy straw, wheat straw and corn straw were collected in farmland around Sichuan Agricultural University. The straw was dried, cut and put into the muffle furnace, and carbonized at 500 degrees for two hours to produce biochar.

\subsection{Experimental design}

The Experiment was conducted in a greenhouse at the Chengdu campus of Sichuan Agricultural University from April to June 2019. In April 2019, peach seeds were sown in perlite while watering them in time to keep them moist. In April 2019, the soil was air-dried, passed through a $5-\mathrm{mm}$ sieve and each plastic pot $(15 \mathrm{~cm}$ high, $18 \mathrm{~cm}$ in diameter) was filled with $3 \mathrm{~kg}$ air-dried soil. There were five treatments in the experiment, including addition of rape straw biochar (RB), addition of paddy straw biochar (PB), addition of wheat straw biochar (WB), addition o corn straw biochar (MB) and no addition (CK). The proportion of adding biochar to soil in each pot was $10 \mathrm{~g} / \mathrm{kg}$, and it was blended. All pots were watered every day to keep the soil moist. In April 2019, three uniformly growing seedlings until the seedlings reached a height of $10 \mathrm{~cm}$ (with about seven true leaves) were transplanted into the previously 
prepared plastic pots. The soil moisture content was maintained at $80 \%$ of field capacity. Each treatment was repeated three times, completely randomized block arrangement. At 1 month after the biochar treatments, the plant was harvested, washed with tap water, and rinsed three times with deionized water. And then the plant height was measured with a ruler and the stem diameter was measured with a vernier caliper, the roots, stem, and leaves of each plant were separately harvested in the end. The plant materials were blanched at $110{ }^{\circ} \mathrm{C}$ for $15 \mathrm{~min}$, dried at $75{ }^{\circ} \mathrm{C}$ until reaching a constant weight, and weighed and crushed, which was used to determine the soluble sugar content in various parts of peach seedlings [11].

\subsection{Statistical analyses}

Statistical analysis was carried out by using SPSS 18.0 statistical software. The data were analyzed by one-way ANOVA, with the least significant difference at the 5\% confidence level.

\section{$3 \quad$ Results and Discussion}

\subsection{Effect of biochar on soluble sugar content in peach seedlings}

Table 1. Effect of biochar on soluble sugar content in peach seedlings

\begin{tabular}{ccccc}
\hline Treatments & $\begin{array}{c}\text { Roots } \\
(\mathrm{mg} / \mathrm{g})\end{array}$ & $\begin{array}{c}\text { Stems } \\
(\mathrm{mg} / \mathrm{g})\end{array}$ & $\begin{array}{c}\text { Leaves } \\
(\mathrm{mg} / \mathrm{g})\end{array}$ & $\begin{array}{c}\text { Shoot } \\
(\mathrm{mg} / \mathrm{g})\end{array}$ \\
\hline CK & $87.72 \pm 3.01 \mathrm{a}$ & $33.14 \pm 1.27 \mathrm{~d}$ & $82.39 \pm 2.07 \mathrm{a}$ & $64.76 \pm 1.41 \mathrm{a}$ \\
RB & $55.21 \pm 1.98 \mathrm{~d}$ & $48.54 \pm 1.99 \mathrm{a}$ & $70.84 \pm 2.08 \mathrm{c}$ & $62.79 \pm 0.62 \mathrm{ab}$ \\
PB & $70.79 \pm 2.72 \mathrm{c}$ & $45.49 \pm 1.88 \mathrm{~b}$ & $70.02 \pm 2.65 \mathrm{c}$ & $61.15 \pm 2.34 \mathrm{~b}$ \\
WB & $73.80 \pm 2.76 \mathrm{c}$ & $44.01 \pm 0.84 \mathrm{~b}$ & $76.34 \pm 2.11 \mathrm{~b}$ & $65.14 \pm 1.76 \mathrm{a}$ \\
MB & $82.40 \pm 2.68 \mathrm{~b}$ & $40.76 \pm 1.50 \mathrm{c}$ & $77.57 \pm 2.92 \mathrm{~b}$ & $64.77 \pm 1.31 \mathrm{a}$
\end{tabular}

Value are means \pm standard errors. Means with the same letter within each column are not significantly different at $p<0.05$. $\mathrm{RB}=$ addition of rape straw biochar, $\mathrm{PB}=$ addition of paddy straw biochar, $\mathrm{WB}=$ addition of wheat straw biochar, $\mathrm{MB}=\mathrm{addition}$ of corn straw biochar.

The soluble sugar content in roots, stems and leaves of peach seedlings all treatments added with biochar was significant difference compared with the control (Table 1). The soluble sugar content in roots and leaves of peach seedlings the treatment of adding biochar was lower than control. The soluble sugar content in roots decreased by $37.06 \%, 19.3 \%, 5.87 \%$ and $6.1 \%$ under the treatment of $\mathrm{RB}, \mathrm{PB}, \mathrm{WB}$ and $\mathrm{MB}$ compared with the control, respectively. The soluble sugar content in leaves decreased by $14.02 \%, 15.01 \%, 7.34 \%$ and $5.85 \%$ under the treatment of $\mathrm{RB}, \mathrm{PB}, \mathrm{WB}$ and $\mathrm{MB}$ compared with the control, respectively. The soluble sugar content in stems increased by $46.47 \%, 37.27 \%, 32.8 \%$ and $22.99 \%$ under the treatment of RB, PB, WB and MB compared with the control, respectively. In the soluble sugar content in the shoot, there was no significant difference between the treatment of adding biochar and the control except for the treatment of PB.

\subsection{The plant height}

All the treatments of adding biochar increased the plant height of peach seedlings except the treatment of MB than the control and the differences can do reach significant levels (Fig. 1). The stem diameters of peach seedlings of three treatments (RB, $\mathrm{PB}$ and $\mathrm{WB}$ ) were $19.63 \%, 9.65 \%$ and $2.51 \%$ respectively, higher than the control. The plant height of peach seedlings each treatment from highest to lowest: $\mathrm{PB}>\mathrm{RB}>\mathrm{WB}>$ $\mathrm{CK}>\mathrm{MB}$. 


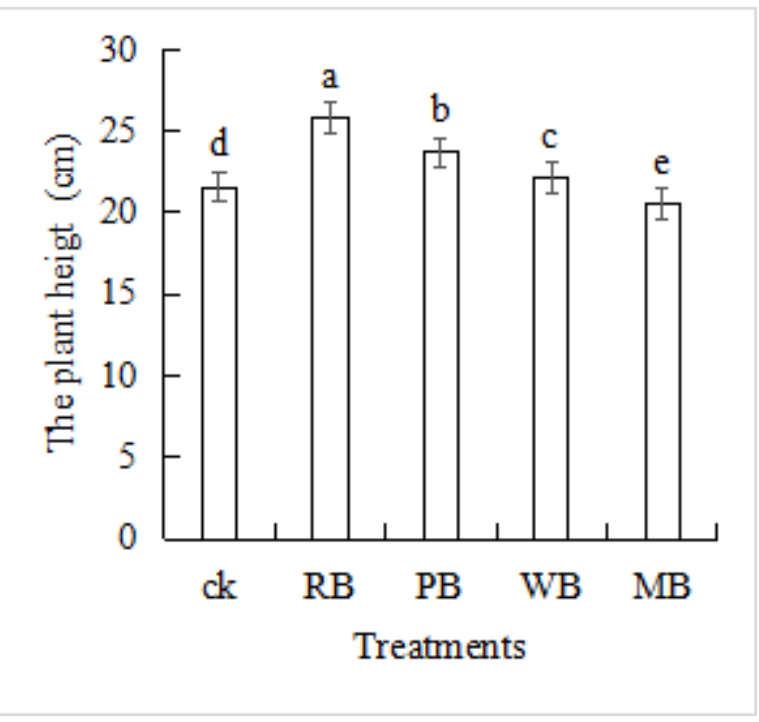

Figure 1. The plant height. Different lowercase letters indicate significant differences based on one-way analysis of variance in SPSS 18.0 followed by the least significant difference test $(p<0.05)$. RB = addition of rape straw biochar, $\mathrm{PB}=$ addition of paddy straw biochar, $\mathrm{WB}=$ addition of wheat straw biochar, $\mathrm{MB}=$ addition of corn straw biochar.

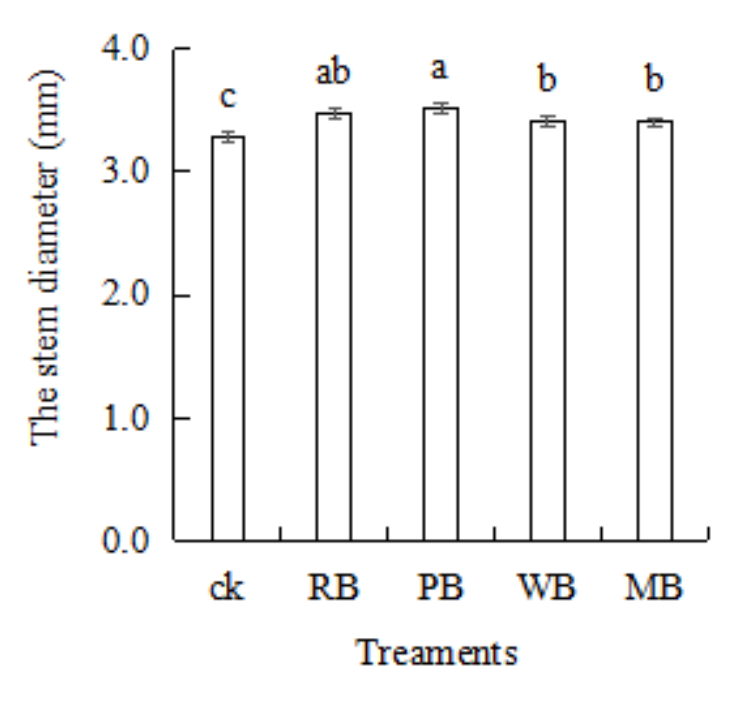

Figure 2. The stem diameter. Different lowercase letters indicate significant differences based on one-way analysis of variance in SPSS 18.0 followed by the least significant difference test $(p<0.05)$. $\mathrm{RB}=$ addition of rape straw biochar, $\mathrm{PB}=$ addition of paddy straw biochar, $\mathrm{WB}=$ addition of wheat straw biochar, $\mathrm{MB}=$ addition of corn straw biochar.

\subsection{The stem diameter}

There were significant levels between the control and the treatment of adding biochar (RB, PB, WB and MB) (Fig. 2). Compared to control, all biochar addition treatments increased stem diameter of peach seedlings and four treatments were $5.88 \%, 7.16 \%, 3.67 \%$ and $3.6 \%$ respectively, higher than the control. The stem diameter of peach seedlings each treatment from highest to lowest: $\mathrm{PB}>\mathrm{RB}>\mathrm{WB}>\mathrm{MB}>\mathrm{CK}$.

\section{Conclusions}

According to the experiment, the soluble sugar content in roots and leaves of peach seedlings treated with biochar was lower than the control. On the contrary, the soluble sugar content in stems was higher than the control. In the soluble sugar content in the shoot, there was no significant difference between the treatment of adding biochar and the control except for the treatment of PB. All the treatments of biochar added increased the plant height of peach seedlings except the treatment of MB than the control and the treatment of RB and PB was at a higher level. Compared to control, all treatments added with biochar increased stem diameter of peach seedlings and the treatment of RB and PB was at a higher level. Therefore, the treatment of RB and PB was beneficial to the growth of peach seedlings.

\section{Acknowledgments}

This work was financially supported by the National Key Research and Development Plan of China (2018YFD0201400).

\section{References}

1. Chen, W.F., Zhang, W.M., Meng, J., Xu, Z.J. (2011) Researches on biochar application technology. Eng. Sci., 13: 83-89.

2. Glaser, B., Lehmaan, J., Zech, W. (2002) Ameliorating physical and chemical properties of highly weathered soils in the tropics with chareoal: a review. Biol. Fertil. Soils, 35: 219-230.

3. Steiner, C., Glaser, B., Teixeira, W.G., Lehmann, J., Blum,W.E.H., Zech, W. (2008) Nitrogen retention and plant uptake on a highly weathered central Amazonian Ferralsol amended with compost and charcoal. Plant Nut. Soil Sci., 171: 893-899.

4. Liang, B.Q., Lehmann. J., Solomon, D., Kinyangi, J. (2006) Black carbon increases cation exchange capacity in soils. Soil Sci. Soc. Am. J., 70: 17191730.

5. Schmidt, M.W.I., Noack, A.G. (2000) Black carbon in soils and sediments: analysis, distribution, implications, and current challenges. Global Biol. Cycles, 14: 777-793.

6. Glascr, B., Haumaier, L., Guggenberger, G., Zech, W. (2001) The 'Terra Preta' phenomenon: a model for sustainable agriculture in the humid tropics. Natur Wissens Charon, 88: 37-41.

7. Liu, S.J., Dou, S. (2009) The Effects of Black Carbon on Growth of Maize and the Absorption and Leaching of Nutrients. J. Soil Water Conserv., 23: 79-82.

8. Gao, F., Yang, F.J., Wu, X., Zhao, L.Q., Li, Y.Z., Song, Y.J., Yu, B.L. (2019) Effects of biochar application on organic matter content and enzyme 
activity in rhizosphere soil of Chinese cabbage. Chin. J. Soil Sci., 50: 103-108.

9. Yang, Q., Li, D.K., Wang, Y.B., Li, Z.L., Li, H.W., Shen, Y.Y. (2016) Effect of different utilization of residue on soybean growth and soil microbial activity. J. South. Univ. Nation. (Nat. Sci.). 42: 591597.

10. Bao, S.D. (2000) Agrochemical soil analysis. China Agriculture Press, Beijing.

11. Hao, Z.B., Cang, J., Xu, Z. (2004) Plant physiology experiment. The Polytechnic University of Harbin Press, Harbin, China. 